Review

\title{
Protection and Reinforcement of Tooth Structures by Dental Coating Materials
}

\author{
Toru Nikaido ${ }^{1, *}$, Rena Takahashi ${ }^{1}$, Meu Ariyoshi ${ }^{1}$, Alireza Sadr ${ }^{2}$ and Junji Tagami ${ }^{1,2}$ \\ 1 Cariology and Operative Dentistry, Department of Oral Health Sciences, Graduate School of \\ Medical and Dental Sciences, Tokyo Medical and Dental University, 1-5-45 Yushima, Bunkyo-ku, \\ Tokyo 113-8549, Japan; E-Mails: renatakahashi@hotmail.com (R.T.); \\ ariyoshipirro@yahoo.co.jp (M.A.); tagami.ope@tmd.ac.jp (J.T.) \\ 2 Global Center of Excellence Program, International Research Center for Molecular Science in \\ Tooth and Bone Diseases, Tokyo Medical and Dental University, 1-5-45 Yushima, Bunkyo-ku, \\ Tokyo 113-8549, Japan; E-Mail: alireza.ope@tmd.ac.jp \\ * Author to whom correspondence should be addressed; E-Mail: nikaido.ope@tmd.ac.jp; \\ Tel.: +81-3-5803-5483; Fax: +81-3-5803-0195.
}

Received: 11 June 2012; in revised form: 5 September 2012 / Accepted: 12 September 2012 / Published: 1 October 2012

\begin{abstract}
It has been proposed that a resin coating can serve as a means to protect dental structure after preparation of the tooth for indirect restorations, sealing the exposed dentin. The resin coating is applied on the cut surfaces immediately after tooth preparation and before making an impression by assembling a dentin bonding system and a flowable composite. Resin coatings minimize pulp irritation and improve the bond strength between a resin cement and tooth when bonding the restoration to tooth. Recently, thin-film coating dental materials based on all-in-one adhesive technology were introduced for resin coating of indirect restorations. The thin coating materials are applied in a single clinical step and create a barrier-like film layer on the prepared dentin. The thin coatings play an important role in protecting the dentin from physical, chemical, and biological irritation. In addition, these thin-film coating materials reportedly prevent marginal leakage beneath inlays or crown restorations. In light of the many benefits provided by such a protective layer, these all-in-one adhesive materials may therefore also have the potential to cover exposed root dentin surfaces and prevent caries formation. In this paper, recent progress of the dental coating materials and their clinical applications are reviewed.
\end{abstract}


Keywords: minimal intervention; adhesive dentistry; dentin bonding; hybrid layer; acid-base resistant zone; resin coating technique; super dentin

\section{Introduction}

Dentin is the main hard substance of the tooth which is covered by enamel on the crown and cementum on the root. Dentin is the calcified product of the odontoblasts which line the inner surface of the dentin within the periphery of the external pulp tissue. Therefore, the dentin and pulp are morphologically and embryologically a single unit. Dental caries (tooth decay) is a multi-factorial disease associated with a cariogenic diet and microbiological invasion of the teeth that result in localized dissolution and destruction of the calcified tissues. It is essential to understand that cavitations in teeth (destruction of the tooth surface, creating a cavity) are signs of dominant loss of mineral from tooth as a result of bacterial acid production. In clinical practice, it is possible to lose sight of this fact and focus entirely on the restorative treatment of the lesion, thereby failing to treat the underlying cause of the disease. Those parts of dentin which are already infected by the bacteria and lost their structural integrity (known as caries-infected dentin) should be removed in the procedure of preparing the tooth for a restoration (Figure 1). Conventionally, intact and sound dental tissues were removed to establish the mechanical retention form of the cavity to avoid failure of the restoration, which were performed by materials without a strong adhesion to the tooth. Nowadays, the concept of minimal cavity preparation which requires only the infected parts to be removed has become widely accepted for the placement of direct composite restorations by using an adhesive system $[1,2]$.

Figure 1. Conventional and minimal invasive caries treatments: (a) cavitated dentin caries; (b) in the conventional restorations, sound dentin was sacrificed to obtain mechanical retention of the restorations; (c) minimal cavity preparation can be achieved for direct composite restorations by using adhesive systems.

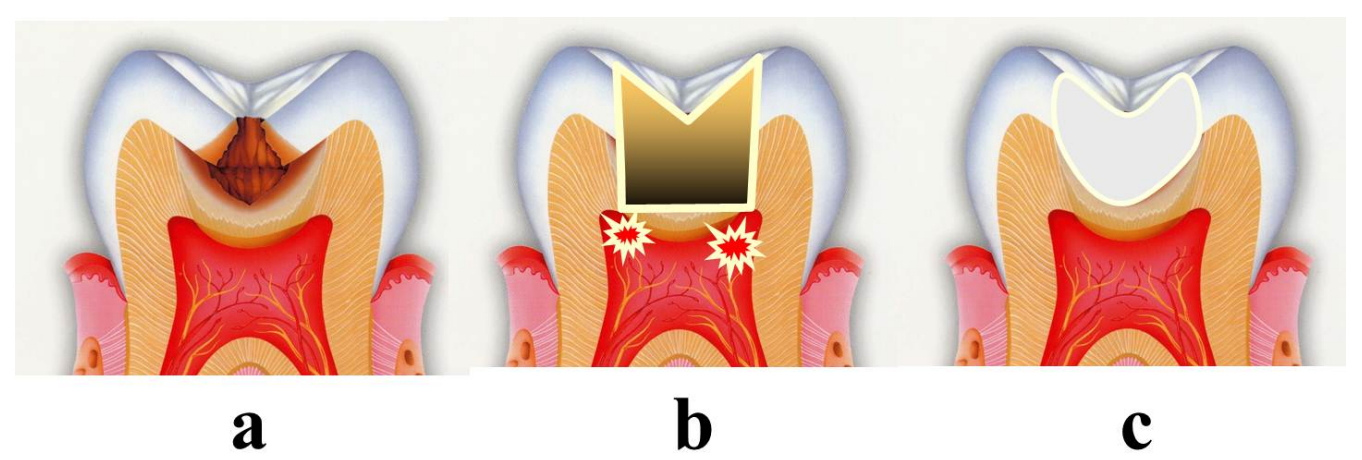

\section{Advances in Adhesive Materials}

Recent dentin bonding systems have been improved and simplified, and can be classified into two main categories; self-etching systems and acid etching systems as shown in Figure 2. The category of self-etching systems is further divided into two sub-categories; two-step self-etching systems and one-step self-etching systems, or so-called "all-in-one adhesive systems". 
Figure 2. Classification of dentin bonding systems; Dentin bonding systems are improved and simplified.

\section{Dentin Bonding Systems}

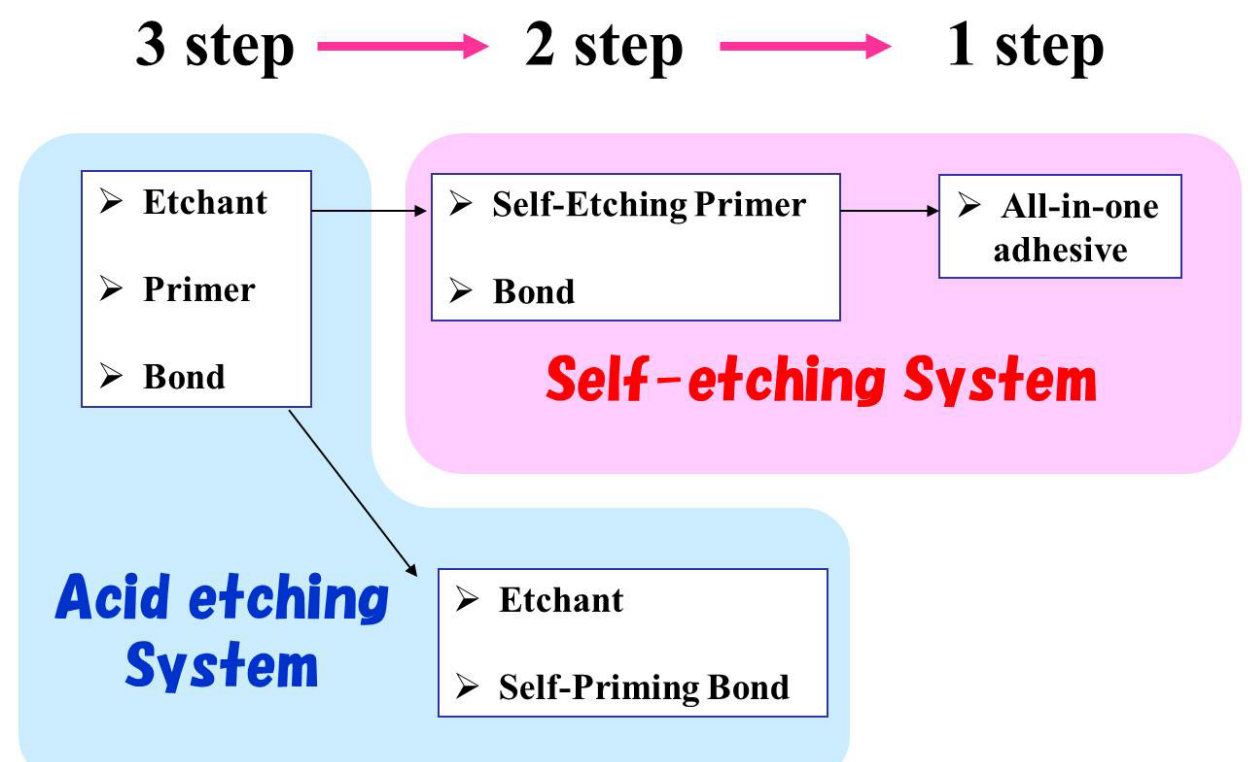

Monomer penetration into dentin and its polymerization in situ creates a hybrid layer, which is essential to obtain good bonding to dentin [3]. Theoretically, the hybrid layer can provide marginal sealing of the cavity and resist against acid challenge to prevent secondary caries [2]. On the other hand, recurrent caries is still considered to be one of the major reasons for replacement of resin composite restorations [4]. Tsuchiya and others foremost observed artificial secondary caries inhibition around adhesive restorations [5]. The dentin surface was demineralized by the acid challenge to create the outer lesion (OL). A new zone, the so called "acid-base resistant zone" (ABRZ) beneath the hybrid layer was found adjacent to OL (Figure 3). These regions with apatite crystallites were expected to be continuous with the normal dentin (Figure 4) [6]. This zone was created only in the self-etching systems, but not in the acid etching systems [7]. The ABRZ should be ascribed to an effective diffusion of the acidic monomer of the self-etching system beyond the hybrid layer, and their chemical bonding potential with apatite as the substrate. Based on the attributes of this zone, which was more resistant against acidic and basic attack compared to the underlying normal dentin, the reinforced dentin was proposed to be called as "Super Dentin" [8], which should be superior to the normal dentin mechanically, chemically and biologically.

Previous studies reported that the ABRZ was also observed at the adhesive-enamel interface in the two-step self-etching system, in which a functional monomer, 10-methacryloxydecyl dihydrogen phosphate (MDP), was included either in the primer or in the bonding agent [9]. It has been found that MDP interacts chemically with hydroxyapatite intensively and stably [10]. This monomer is capable of forming strong ionic bonds with calcium, producing MDP-calcium salts that have a low solubility. The enamel ABRZ demonstrated an increased resistance of the interface to acid challenge, suggesting the "Super Enamel" formation. Using the self-etching technology, formation of "Super Dentin/Enamel" may become a key strategy to protect and reinforce tooth structures. 
Figure 3. Acid-base resistant zone (ABRZ) is created beneath the hybrid layer, which is expected to resist against demineralization from an acid attack from the microorganisms in primary and secondary caries. The reinforced dentin was proposed to be called as "Super Dentin”. CR; resin composite, B; bonding resin, OL; outer lesion.

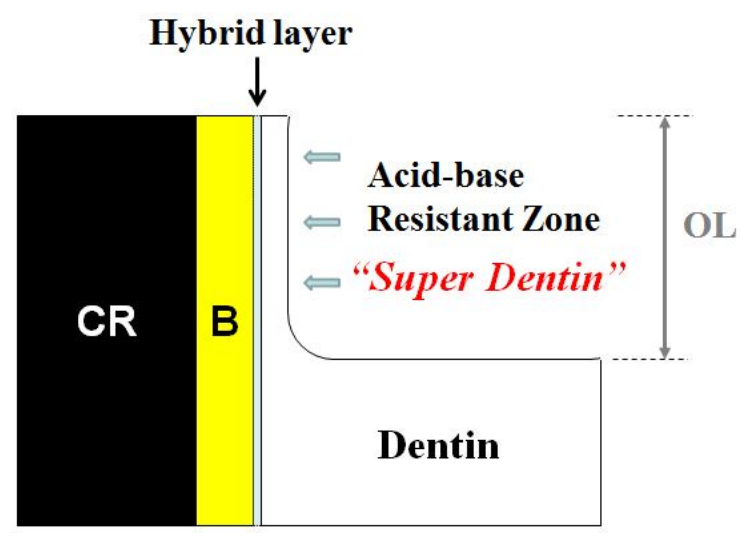

Figure 4. TEM image of the interface between a two-step self-etch adhesive system (Clearfil SE Bond, Kuraray Noritake Dental, Tokyo, Japan) and dentin after acid-base challenge. The specimen was first subjected to $100 \mathrm{~mL}$ buffered demineralizing solution ( $\mathrm{pH}$ 4.5, $2.2 \mathrm{mmol} / \mathrm{L} \mathrm{CaCl}_{2}, 2.2 \mathrm{mmol} / \mathrm{L} \mathrm{NaH}_{2} \mathrm{PO}_{4}$ and $50 \mathrm{mmol} / \mathrm{L}$ acetic acid) for $90 \mathrm{~min}$ to create artificial secondary caries, and then to $5 \% \mathrm{NaClO}$ for $30 \mathrm{~min}$ to remove any denatured collagen fibrils. The ABRZ with apatite crystallites ("Super Dentin") were expected to be continuous with the dentin. Magnification; $\times 7740, \mathrm{~B}$; bonding resin, $\mathrm{H}$; hybrid layer, D; dentin, OL; outer lesion [6].

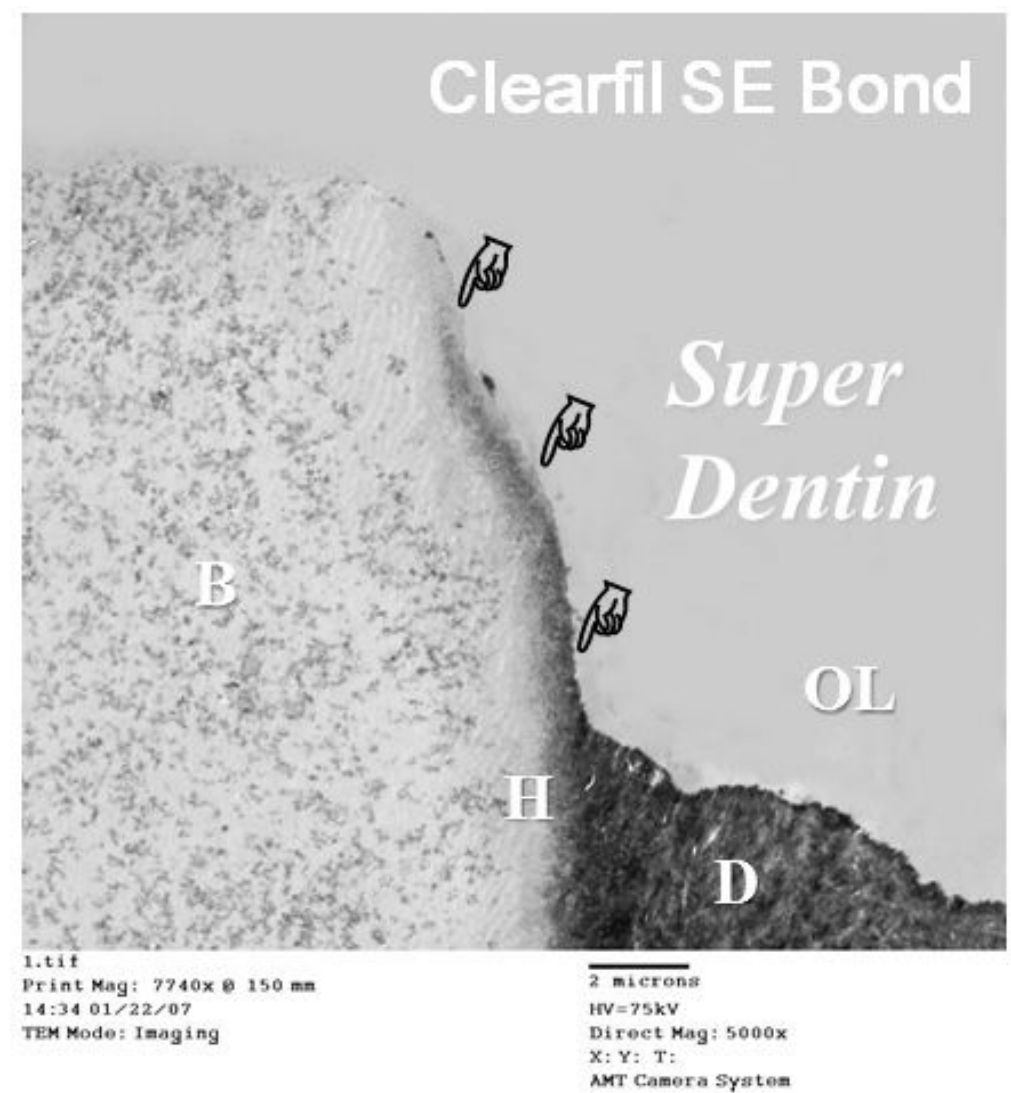




\section{Resin Coating Technique in Indirect Restoration}

As described above, recent advances in adhesive materials and technologies have resulted in the routine placement of adhesive restorations in the clinic. Direct composite restorations are the preferred treatment over indirect restorations because of the achievement of the minimal intervention concept [1,2]. Indirect restorations are still among the main options when the prepared cavity is extensive. However, conventional inlay/onlay restorations have some inherent drawbacks. When a cavity is prepared for an indirect inlay/onlay restoration, intact tooth structure has to be sacrificed to obtain the retention and resistance forms, especially because the conventional luting cements have a poor capability of bonding to tooth structure (see Figure 1b,c). Furthermore, dentin exposed after cavity preparation ought to be considered as a pulp tissue indirect exposure, since dentin is connected to pulp tissue through dentinal tubules. Therefore, the exposed dentin should be protected immediately after the preparation. Although temporary sealing of the prepared cavities has routinely been performed, the poor sealing with such a temporary material may easily fail, resulting in accidental exposure of the prepared dentin in the oral cavity, and irrigation from physical, chemical and/or bacterial stimuli $[11,12]$.

Without doubt, the sealing property of modern dentin adhesive systems is superior to those of the temporary sealing materials [13]. A previous study also demonstrated that a recent dentin bonding system has good biocompatibility to pulp tissue [14]. In order to protect the exposed dentin surface after cavity preparation for indirect restorations, a resin coating technique was proposed in the early 1990's [15,16]. The clinical procedures of the resin coating technique are illustrated in Figure 5. For the resin coating technique, a combination of a dentin bonding system and a flowable resin composite was applied on the preparation just after cavity preparation and before taking the impression, producing a hybrid layer and tight sealing film are produced on the dentin surface using a combination of a dentin bonding system and a flowable composite (Figure 6) [17].

Figure 5. The clinical procedures of the resin coating technique. A combination of a dentin bonding system and a flowable resin composite is applied on the preparation just after cavity preparation and before taking the impression.

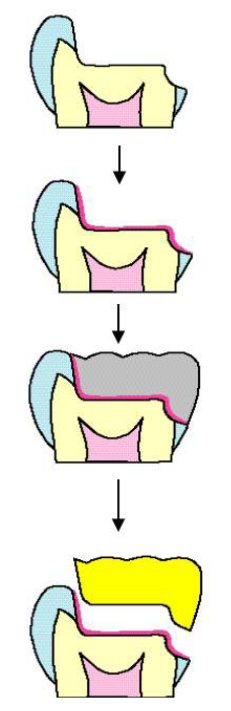

\section{Cavity preparation}

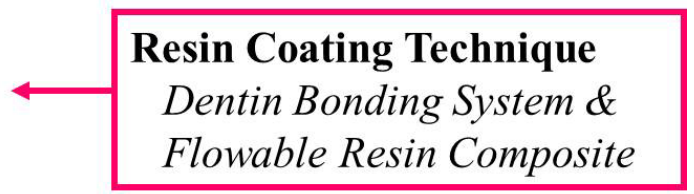

Taking Impression Temporization

\section{Bonding}


Figure 6. The resin coating technique produces a hybrid layer and tight sealing film on the dentin surface and protect dentin-pulp complex.

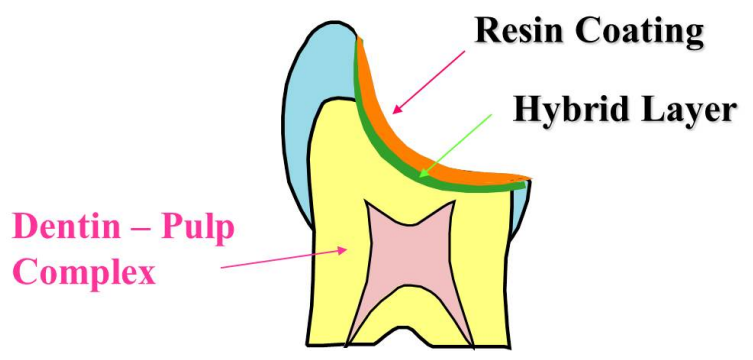

This technique is beneficial in improving the dentin adhesion of a resin cement for indirect restorations and enhancing marginal integrity $[18,19]$. However, selection of the coating material influences immediate dentin bonding performance [20] and also dentin bonding durability [21,22]. If a good bonding is obtained using the resin coating technique, removal of intact tooth structure would be unnecessary for retention and/or resistance form. According to the Black's principles, sacrifice of the dental tissue is required to establish mechanical retention and resistance of restoration; however, in the new concept of adhesion, only the infected caries should be removed, thus preserving the caries-affected dentin and intact dentin even when teeth have extensive caries. When the lost tooth structure is to be replaced by an indirect restoration, the exposed enamel and dentin should be immediately sealed using the resin coating technique. This rational approach to adhesion has a positive influence on tooth structure preservation, patient comfort, and the long-term survival of indirect bonded restorations. Therefore, the resin coating technique has the potential for introducing the minimal intervention concept into indirect restorations [11].

Paul et al. and Bertschinger et al. reported "dual application" [23,24]. Magne et al. proposed "immediate dentin sealing (IDS)" [25,26]. These ideas are believed to share the same concepts of the resin coating technique.

The idea of having an additional resin coating placed on the preparation raised concernes about the thickness of the coating and possible interferences with complete seating of the restoration. This dilemma was resolved by proper sequencing of the procedure and placement of the coating material before impression making. In addition, the incompletely polymerized resin coating can inhibit the polymerization reaction of impression materials, which depends on selection of the materials [27]. The contamination of the resin coating by the temporary filling material also remains an issue, as it may alter the bond between the existing resin coating and the luting agent [20,27]. Further studies are needed to elucidate the exact mechanism of these interactions, allowing the optimization of the coating materials and the development of surface conditioners for the application of the resin coating technique.

\section{Development of Thin Film Coating Materials}

The combination of a dentin bonding system and a low viscosity micro-filled resin creates a thick coating layer, more than $100 \mu \mathrm{m}$ in thickness, on the dentin surface. Such a thick coating is not suitable for a crown preparation, because of the possibility of deformation of the preparation by the resin coating [28]. 
Recently, a thin-film coating material has been developed by using the all-in-one adhesive technology. Such coating materials are clinically used for sealing the crown preparation and also for desensitizing the hypersensitive dentin. Application of the coating material can create a thin coating layer with less than $10 \mu \mathrm{m}$ in thickness on the dentin surface, which is useful for the resin coating materials of the crown preparation (Figure 7). It was demonstrated that the thin-film coating material improved the dentin bonding performance of resin cement, and prevented marginal leakage beneath the restorations $[12,19,29]$.

We are now able to select the two different application methods for the resin coating, such as a combination of a dentin bonding system and a flowable resin composite, and a thin film coating material. The combination method demonstrates more reliable dentin bonding performance than the thin film coating. However, the resin coating with the thin film coating material is easily removed even in the gingival sulcus after curing. Therefore, the two coating methods should be chosen according to the clinical cases of the indirect restorations.

Figure 7. Thin-film coating for sealing the crown preparation.

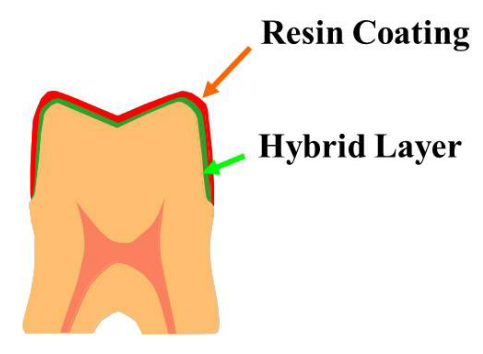

\section{Dental Coating Materials in the Future}

Recent years have seen a rapid increase in the dentate elderly population, especially in developed countries, due to increase in life expectancy, awareness of dental health measures, and availability of dental care delivery systems. However, a concomitant development is the increasing incidences of root caries, tooth wear and tooth fracture in the middle-aged and elderly. These incidences are potentially important risk factors causing tooth loss. To achieve a good quality of life, it is important to maintain natural tooth structures sound for the whole life.

The concept of pit and fissure sealing with composite resins has been widely accepted for enamel caries prevention in children and young adults [30]. Recently, approaches have been made to extend this preventive concept to smooth enamel surfaces [31,32]. The superficial penetration and surface coating of the adhesive and/or caries infiltrant is considered as a treatment option for protecting enamel dissolution [33].

Soft tissue recession due to age, traumatic toothbrush habits, periodontal disease or surgical periodontal treatment will unavoidably result in exposure of susceptible root surface and the high incidence of root caries and dentin hypersensitivity [34]. Simple single-visit methods to protect the exposed root surfaces from long-term caries attack are advantageous. However, a promising approach to prevent root caries has not become available yet.

Root surface coating with the dentin bonding systems is considered to be an effective measure for protection against caries, erosion and abrasion [35], as it provides a strong physical barrier with the 
formation of "Super Dentin" (Figure 8). From the clinical stand point, to control the biofilm adherence on the coating material is also important to reduce caries risk in the oral environment [36]. A series of experimental coating materials with self-cleaning surface property have been developed, which demonstrated such surface property had good potential to inhibit biofilm adherence [37] (Figure 9). If such materials with a surface property could be combined with the current adhesive technology, the surface coating will become a promising therapy in preventive dentistry in the future.

Figure 8. Surface coating strategy in the future; Surface coating can provide a strong physical barrier with the formation of "Super Dentin" and also "Super Enamel" for protection against caries, erosion and abrasion.

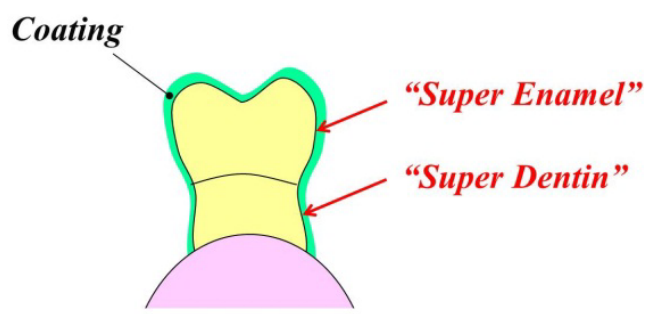

Figure 9. Root surface coating with the dentin bonding systems; Covering the exposed root dentin surfaces using the coating materials have the potential to become an effective therapy to prevent root dentin caries.

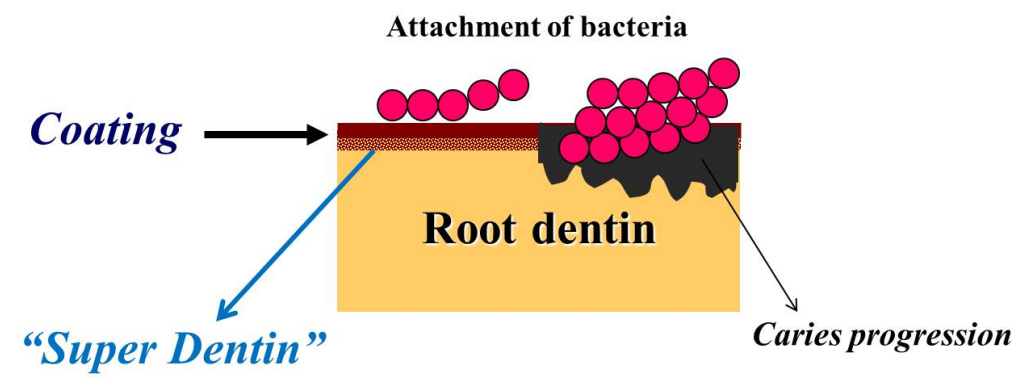

\section{Acknowledgements}

This work was supported by the grant from the Global Center of Excellence (GCOE) Program, International Research Center for Molecular Science in Tooth and Bone Diseases at Tokyo Medical and Dental University and a Grant-in Aid from the Japan Society for the Promotion of Science (JSPS No. 22592116).

\section{References}

1. Tyas, M.J.; Anusavice, K.J.; Frencken, J.E.; Mount, G.J. Minimal intervention dentistry-A review, FDI Commission Project 1-97. Int. Dent. J. 2000, 50, 1-12.

2. Momoi, Y.; Fujitani, M.; Fukushima, M.; Hayashi, M.; Imazato, S.; Kubo, S.; Nikaido, T.; Shimizu, A.; Unemori, M.; Yamaki, M. Clinical guidelines for treating caries in adults following a minimal intervention policy, evidence and consensus based report. J. Dent. 2012, 40, 95-105.

3. Nakabayashi, N.; Nakamura, M.; Yasuda, N. Hybrid layer as a dentin bonding mechanism. J. Aesthet. Dent. 1991, 3, 133-138. 
4. Fontana, M.; Gonzalez-Cabezas, C. Secondary caries and restoration replacement: An unresolved problem. Compend. Contin. Educ. Dent. 2000, 21, 15-26.

5. Tsuchiya, S.; Nikaido, T.; Sonoda, H.; Foxton, R.M.; Tagami, J. Ultrastructure of the dentin-adhesive interface after acid-base challenge. J. Adhes. Dent. 2004, 6, 183-190.

6. Waidyasekera, K.; Nikaido, T.; Weerasinghe, D.S.; Ichinose, S.; Tagami, J. Reinforcement of dentin in self-etch adhesive technology: A new concept. J. Dent. 2009, 37, 604-609.

7. Nurrohman, H.; Nikaido, T.; Takagaki, T.; Sadr, A.; Ichinose, S.; Tagami, J. Hydroxyapatite crystal protection against acid-attack beneath resin-dentin interface with four adhesives. TEM and crystallography evidence. Dent. Mater. 2012, 28, e89-e98.

8. Nikaido, T.; Weerasinghe, D.D.; Waidyasekera, K.; Inoue, G.; Foxton, R.M.; Tagami, J. Assessment of the nanostructure of acid-base resistant zone by the application of all-in-one adhesive systems: Super dentin formation. Biomed. Mater. Eng. 2009, 19, 163-171.

9. Li, N.; Nikaido, T.; Takagaki, T.; Sadr, A.; Makishi, P.; Chen, J.; Tagami, J. The role of functional monomers in bonding to enamel: Acid-base resistant zone and bonding performance. J. Dent. 2010, 38, 722-730.

10. Yoshida, Y.; Nagakane, K.; Fukuda, R.; Okazaki, M.; Shintani, H.; Inoue, S.; Tagawa, Y.; Suzuki, K.; De Munck, J.; Van Meerbeek, B. Comparative study on adhesive performance of functional monomers. J. Dent. Res. 2004, 83, 454-458.

11. Nikaido, T.; Yoda, A.; Foxton, R.M.; Tagami, J. A resin coating technique to achieve minimal intervention in indirect resin composites: A case report. Int. Chin. J. Dent. 2003, 3, 62-68.

12. Islam, M.R.; Takada, T.; Weerasinghe, D.S.; Uzzaman, M.A.; Foxton, R.M.; Nikaido, T.; Tagami, T. Effect of resin coating on adhesion of composite crown restoration. Dent. Mater. J. 2006, 25, 272-279.

13. Pashley, E.L.; Comer, R.W.; Simpson, M.D.; Horner, J.A.; Pashley, D.H.; Caughman, W.F. Dentin permeability: Sealing the dentin in crown preparations. Oper. Dent. 1992, 17, 13-20.

14. Kitasako, Y.; Murray, P.E.; Tagami, J.; Smith, A.J. Histomorphometric analysis of dentinal bridge formation and pulpal inflammation. Quintessence. Int. 2002, 33, 600-608.

15. Inokoshi, S. Temporary sealing-pulp and dentin protection using low viscosity composite (in Japanese). Adhes. Dent. 1992, 10, 250.

16. Sato, M.; Goto, H.; Inai, N.; Nikaido, T.; Tagami, J.; Inokoshi, S.; Yamada, T.; Takatsu, T. How to use "Liner Bond System" as a dentin and pulp protector in indirect restorations (in Japanese). Adhes. Dent. 1994, 12, 41-48.

17. Otsuki, M.; Yamada, T.; Inokoshi, S.; Takatsu, T.; Hosoda, H. Establishment of a composite resin inlay technique part 7. Use of low viscous resin (in Japanese). Jpn. J. Conserv. Dent. 1993, 36, 1324-1330.

18. Jayasooriya, P.R.; Pereira, P.N.R.; Nikaido, T.; Tagami, J. Effect of a "Resin-coating" on the interfacial adaptation of composite inlays. Oper. Dent. 2003, 28, 28-35.

19. Kosaka, S.; Kajihara, H.; Kurashige, H.; Tanaka, T. Effect of resin coating as a means of preventing marginal leakage beneath full cast crowns. Dent. Mater. J. 2005, 24, 117-122.

20. Nikaido, T.; Cho, E.; Nakajima, M.; Tashiro, H.; Toba, S.; Burrow, M.F.; Tagami, J. Tensile bond strengths of resin cements to bovine dentin using resin coating. Am. J. Dent. 2003, 16, 41 A-46A. 
21. Kitasako, Y.; Burrow, M.F.; Nikaido, T.; Tagami, J. Effect of resin coating technique on dentin bond strengths over 3 years. J. Esthet. Restor. Dent. 2002, 14, 115-122.

22. Nikaido, T.; Kitasako, Y.; Burrow, M.F.; Umino, A.; Maruoka, R.; Ikeda, M.; Tagami, J. Effect of resin coating on dentin bond durability of a resin cement over 1 year. Am. J. Dent. 2008, 21, 64-68.

23. Paul, S.J.; Schärer, P. The dual bonding technique: A modified method to improve adhesive luting procedures. Int. J. Periodontics Restor. Dent. 1997, 17, 536-545.

24. Bertschinger, C.; Paul, S.J.; Lüthy, H.; Schärer, P. Dual application of dentin bonding agents: Effect on bond strength. Am. J. Dent. 1996, 9, 115-119.

25. Magne, P. Immediate dentin sealing: A fundamental procedure for indirect bonded restorations. J. Esthet. Restor. Dent. 2005, 17, 144-154.

26. Magne, P.; Kim, T.H.; Cascione, D.; Donovan, T.E. Immediate dentin sealing improves the bond strength of indirect restorations. J. Prosthet. Dent. 2005, 94, 511-519.

27. Magne, P.; Nielsen, B. Interaction between impression materials and immediate dentin sealing. J. Prosthet. Dent. 2009, 102, 298-305.

28. Nikaido, T.; Nakaoki, Y.; Ogata, M.; Foxton, R.M.; Tagami, J. The resin-coating technique. Effect of a single-step bonding system on dentin bond strengths. J. Adhes. Dent. 2003, 5, 293-300.

29. Takahashi, R.; Nikaido, T.; Ariyoshi, M.; Kitayama, S.; Sadr, A.; Foxton, R.M.; Tagami, J. Thin resin coating by dual-application of all-in-one adhesives improves dentin bond strength of resin cements for indirect restorations. Dent. Mater. J. 2010, 29, 615-622.

30. Horowitz, H.S.; Heifetz, S.B.; Poulsen, S. Retention and effectiveness of a single application of an adhesive sealant in preventing occlusal caries: Final report after five years of a study in Kalispell, Montana. J. Am. Dent. Assoc. 1977, 95, 1133-2119.

31. Paris, S.; Meyer-Luekel, H.; Mueller, J.; Hummel, M.; Keilbassa, A.M. Progression of sealed initial vovine enamel lesions under demineralizing conditions in vitro. Caries Res. 2006, 40, 124-129.

32. Phark, J.H.; Durate, S.J.; Meyer-Lueckel, H.; Paris, S. Caries infiltration with resins: A novel treatment option for interproximal caries. Compend. Contin. Educ. Dent. 2009, 30, 13-17.

33. Schmidlin, P.R.; Sener, B.; Attin, T.; Wiefand, A. Protection of sound enamel and artificial enamel lesions against demineralization: Caries infiltrant versus adhesive. J Dent. 2012, 40, $851-856$.

34. Heijnsbroek, M.; Paraskevas, S.; van der Weijden, G.A. Fluoride interventions for root caries: A review. Oral. Health. Prev. Dent. 2007, 5, 145-152.

35. Kaneshiro, A.V.; Imazato, S.; Ebisu, S.; Tanaka, S.; Tanaka, Y.; Sano, H. Effects of a self-etching resin coating system to prevent demineralization of root surfaces. Dent. Mater. 2008, $24,1420-1427$.

36. Daneshmehr, L.; Matin, K.; Nikaido, T.; Tagami, J. Effects of root dentin surface coating with all-in-one adhesive materials on biofilm adherence. J. Dent. 2008, 36, 33-41. 
37. Tajima, K.; Nikaido, T.; Inoue, G.; Ikeda, M.; Tagami, J. Effects of coating root dentin surfaces with adhesive materials. Dent. Mater. J. 2009, 28, 578-586.

(C) 2012 by the authors; licensee MDPI, Basel, Switzerland. This article is an open access article distributed under the terms and conditions of the Creative Commons Attribution license (http://creativecommons.org/licenses/by/3.0/). 